\title{
Acromegaly incidence, prevalence, complications and long-term prognosis: a nationwide cohort study
}

\author{
Jakob Dal', Ulla Feldt-Rasmussen², Marianne Andersen ${ }^{3}$, Lars ø Kristensen ${ }^{4}$, Peter Laurberg ${ }^{5, t}$, \\ Lars Pedersen ${ }^{6}$, Olaf M Dekkers ${ }^{6,7,8}$, Henrik Toft Sørensen ${ }^{6}$ and Jens Otto L Jørgensen ${ }^{1}$
}

${ }^{1}$ Department of Endocrinology and Internal Medicine, Aarhus University Hospital, Aarhus, Denmark, ${ }^{2}$ Department of Endocrinology, National University Hospital, Copenhagen, Denmark, ${ }^{3}$ Department of Endocrinology, Odense University Hospital, Odense, Denmark, ${ }^{4}$ Department of Endocrinology, Herlev Hospital, Copenhagen, Denmark, ${ }^{5}$ Department of Endocrinology, Aalborg University Hospital, Aalborg, Denmark, ${ }^{6}$ Department of Clinical Epidemiology, Aarhus University Hospital, Aarhus N, Denmark, ${ }^{7}$ Department of Medicine, Section of Endocrinology, and ${ }^{8}$ Department of Clinical Epidemiology, Leiden University Medical Center, Leiden, The Netherlands ${ }^{\dagger}$ Deceased

Correspondence should be addressed to J Dal Email Jakob.dal@dadlnet.dk

\begin{abstract}
Design: Valid data on acromegaly incidence, complications and mortality are scarce. The Danish Health Care System enables nationwide studies with complete follow-up and linkage among health-related databases to assess acromegaly incidence, prevalence, complications and mortality in a population-based cohort study.

Method: All incident cases of acromegaly in Denmark (1991-2010) were identified from health registries and validated by chart review. We estimated the annual incidence rate of acromegaly per $10^{6}$ person-years (py) with $95 \%$ confidence intervals $(95 \% \mathrm{Cls})$. For every patient, 10 persons were sampled from the general population as a comparison cohort. Cox regression and hazard ratios (HRs) with $95 \%$ confidence intervals $(95 \% \mathrm{Cls}$ ) were used. Results: Mean age at diagnosis (48.7 years ( $\mathrm{Cl}: 95 \%: 47.2-50.1)$ ) and annual incidence rate $\left(3.8\right.$ cases $/ 10^{6}$ persons (95\% Cl: 3.6-4.1)) among the 405 cases remained stable. The prevalence in 2010 was 85 cases $/ 10^{6}$ persons. The patients were at increased risk of diabetes mellitus (HR: 4.0 (95\% Cl: 2.7-5.8)), heart failure (HR: 2.5 (95\% Cl: 1.4-4.5)), venous thromboembolism (HR: 2.3 (95\% Cl: 1.1-5.0)), sleep apnoea (HR: 11.7 (95\% Cl: 7.0-19.4)) and arthropathy (HR: 2.1 (95\% Cl: 1.6-2.6)). The complication risk was also increased before the diagnosis of acromegaly. Overall mortality risk was elevated (HR: $1.3(95 \% \mathrm{Cl}: 1.0-1.7))$ but uninfluenced by treatment modality. Conclusion: (i) The incidence rate and age at diagnosis of acromegaly have been stable over decades, and the prevalence is higher than previously reported. (ii) The risk of complications is very high even before the diagnosis. (iii) Mortality risk remains elevated but uninfluenced by mode of treatment.
\end{abstract}

\section{Introduction}

Acromegaly is a rare condition predominantly caused by a growth hormone (GH)-secreting pituitary adenoma (1). Long-term presence of elevated GH and insulinlike growth factor I (IGF-I) levels is associated with complications such as heart failure, cerebrovascular
() 2016 European Society of Endocrinology Printed in Great Britain
European Journal of Endocrinology

(2016) 175, 181-190 
For these reasons, several consensus statements emphasize the importance of rapid and permanent control of the disease in order to halt and reverse morbidity and mortality $(6,7)$. To optimize therapy and control of the disorder, data on the occurrence and outcome of acromegaly are essential. While data from several studies are published $(2,3)$, a series of issues remain unaddressed. First, accurate estimates of incidence and prevalence rates require population-based studies. Second, assessment of acromegaly-related complications and mortality necessitates long-term and complete follow-up and access to comparative data from the source population. The health care system in Denmark, with free access for patients to general practitioners and hospitals, provides unique opportunities to meet these methodological challenges. The unique civil registration number issued to all residents at birth or immigration permits complete follow-up, linkage among pertinent health-related databases, and provision of large comparison cohorts from the general population.

This study aimed to estimate incidence and prevalence of acromegaly in a population-based cohort study and to compare overall mortality and complications in acromegalic patients and a general population comparison cohort.

\section{Subjects and methods}

\section{Source population and description of databases}

The source population comprised the entire population of Denmark with approximately 7.2 million inhabitants during the 1991-2010 period. Data were obtained from the Danish National Patient Registry (DNPR), the Danish Civil Registration System (DCRS), the Danish Register of Causes of Death (DRCD) and systematic chart review of all patients diagnosed with acromegaly. The DNPR contains records of all hospital discharge diagnoses and surgical procedures since 1977 and all hospital outpatient specialist clinic and emergency department visits since 1995, coded according to the International Classification of Diseases (ICD), 8th and 10th revisions (8). The DCRS has kept electronic records of gender, age, birth date, residence, emigration date and vital status since 1968. The DRCD contains individual digitalized classification of causes of death in accordance with WHO's rules and, since 1994, by ICD-10 codes (9). Accurate linkage of all registries at the individual level is possible using the unique central personal registry number assigned to each Danish resident at birth or immigration. The Danish
National Health Service provides universal tax-supported health care, guaranteeing free access for patients to general practitioners and hospitals (10).

The study protocol was approved by the Danish National Board of Health (j.nr.3-3013-97/1/) and the Danish Data Protection Agency.

\section{Study population}

The acromegaly cohort was identified from the DNPR using ICD-8 codes 25300 and 25301 and ICD-10 code DE220. These codes were recently validated in the DNRP (11). Furthermore, we reviewed each patient's chart to confirm the diagnosis and to extract data on GH and IGF-I levels and the size of the pituitary adenoma.

The general population comparison cohort was drawn from the DCRS. For every acromegaly patient, 10 acromegaly-free persons in the general population were sampled from persons alive on the date of the acromegaly diagnosis (the 'index date'), matched by age and sex. If persons in the comparison cohort developed acromegaly, follow-up was terminated and they started contributing person-time to the exposed cohort.

\section{Laboratory test results and diagnostic imaging}

Serum levels of GH and IGF-I at diagnosis were retrieved from patient charts; maximally suppressed $\mathrm{GH}$ levels during an oral glucose load $\left(\mathrm{GH}_{\text {nadir }}\right)$ were retrieved, where available. Serum IGF-I concentrations were transformed into IGF-I standard deviation scores (IGF-SDSs) on the basis of age- and sex-specific IGF-I normal values. Pituitary adenoma size (maximal diameter) was identified from the diagnostic imaging report, where available.

\section{Start of follow-up}

Follow-up started on the date of the acromegaly diagnosis (date of diagnostic blood sample) and on the matched index date for the comparison cohort members. Follow-up was censored at time of death or emigration, or on 31 December 2012, whichever came first.

It is generally assumed that there is a 5-10 year delay in diagnosing acromegaly (1). This period, therefore, represents untreated exposure time to the disease. To ascertain the impact of the prediagnostic period on morbidity, we conducted a sensitivity analysis in which the follow-up period was confined to 3 years before diagnosis and ended for patients with acromegaly and 
3 years before the index date for matched unexposed cohort members. By definition, risk estimates were based on nonfatal events during these prediagnostic years.

\section{Study endpoints}

We estimated and compared mortality rates in acromegaly patients and the general population cohort. We compared acromegalic patients and the matched population cohort regarding the first diagnosis of heart failure, acute myocardial infarction (AMI), stroke, diabetes mellitus, cancer, sleep apnoea, arthropathy, fracture and venous thromboembolism (VTE). For cause-specific mortality, we defined two groups: cancer-specific mortality, defined as death from any cancer, and cardiovascular mortality, defined as death from a cardiovascular cause. Any death not attributed to either cancer or cardiovascular disease was categorized as 'other'.

Diagnoses in the DNPR were used for endpoint identification. Hospital discharge and outpatient visits are recorded in the DNPR with one primary diagnosis and one or more secondary diagnoses classified according to ICD-8 until the end of 1993 and ICD-10 thereafter. Relevant ICD codes are provided in Appendix 1, see section on Appendix given at the end of this article. For each event examined (heart failure, AMI, stroke, diabetes mellitus, cancer, sleep apnoea, arthropathy, fracture and VTE), we excluded acromegaly patients and comparison cohort members with a diagnosis of the given condition before start of follow-up.

\section{Statistical analysis}

We computed the annual incidence rate of acromegaly per $10^{6}$ person-years with $95 \%$ confidence intervals (95\% CIs). Incidence rates were standardized to the age distribution of the Danish population in the year 2000. Prevalence was calculated per million inhabitants during 2010, the last year of study inclusion. As the prevalence estimation was based on prevalent cases and the study cohort included incident acromegaly patients since 1991, the numerator for prevalence estimation $(n=469)$ was larger than the number of included patients $(n=405)$.

For patients with acromegaly and persons in the population comparison cohort, we calculated the rate of heart failure, AMI, stroke, VTE, diabetes mellitus, hypertension, sleep apnoea, arthropathy, fracture, cancer, mortality and cause-specific mortality. The rates were expressed as the number of events per 1000 person-years. We used Kaplan-Meier analysis to construct survival curves and Cox regression for time-to-event analysis; hazard ratios (HRs) were computed with accompanying 95\% CI. We also performed Cox regression to adjust for potential baseline imbalances, including smoking- and alcoholrelated diagnoses, diabetes mellitus, cancer, obesity and hypertension. The risk of diabetes mellitus, cancer and hypertension was not adjusted for baseline imbalance in diabetes mellitus, cancer and hypertension respectively. The study design included adjustment for age and sex through matching. We conducted two stratified analyses: an analysis stratified by age at diagnosis (age <or $>50$ th percentile, e.g. 48.0 years) and a gender-specific analysis
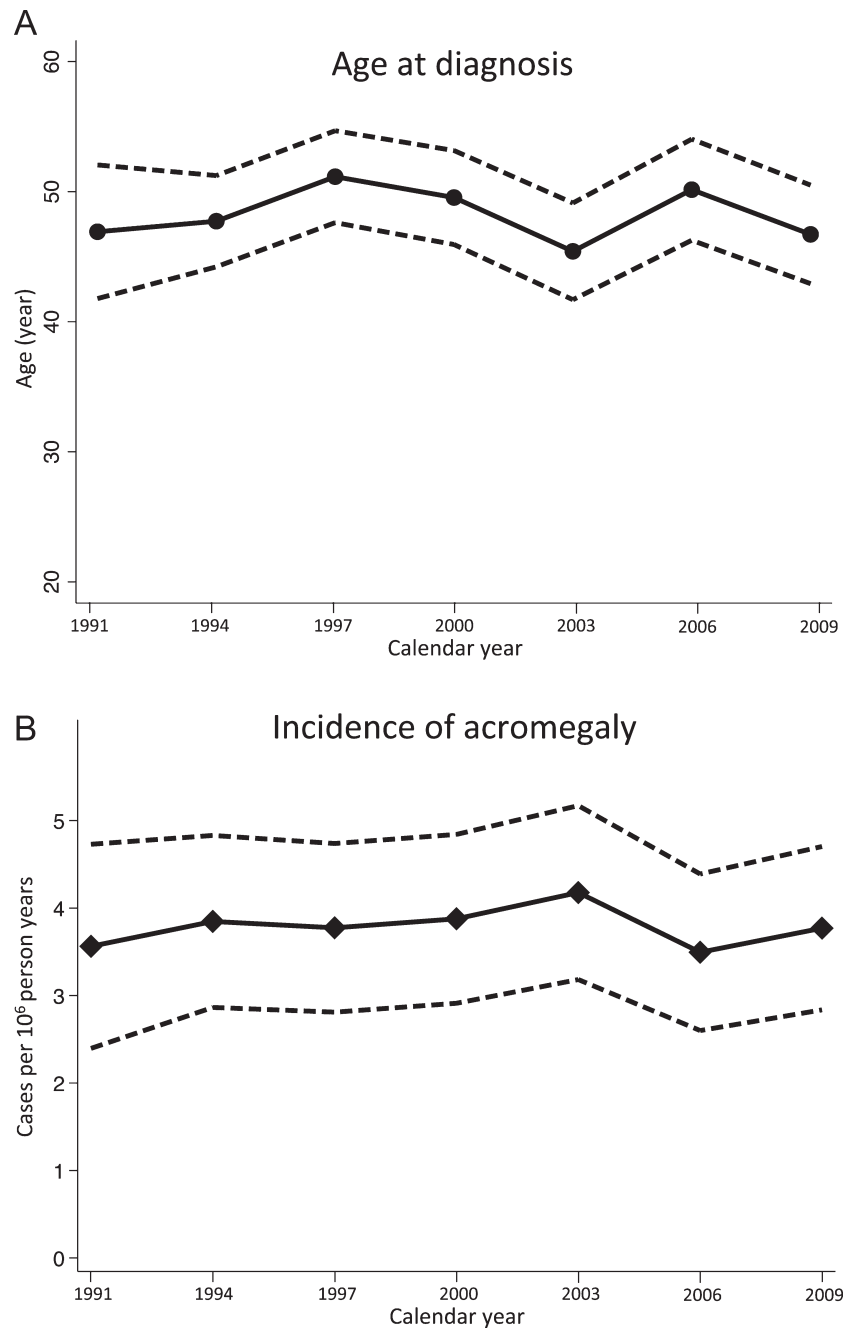

Figure 1

Mean age at acromegaly diagnosis with $95 \%$ confidence intervals over calendar time (A) and annual incidence rate of acromegaly per $10^{6}$ person-years with $95 \%$ confidence intervals standardized to the age distribution of the Danish population in the year 2000 (B). 
of complications. The association between GH and IGF-I and mortality was tested in an age- and sex-adjusted regression model based on logarithmically transformed GH and IGF-I values.

We performed additional analyses to assess the impact of different treatment strategies on mortality and morbidity. This was a within-cohort comparison, without use of a matched comparison cohort. As many treatments or treatment combinations are started after initial diagnosis, immortal time bias is relevant to consider (12). This bias occurs when exposure (e.g. treatment) starts after follow-up and the time until start of exposure is not accounted for appropriately. One way to circumvent immortal time bias is to start follow-up at a standardized point in time, and to determine exposure status at that time point. We, therefore, decided to categorize treatment after 2 years of initial diagnosis. Treatment was categorized as surgery only, medical therapy only (dopamine agonist, somatostatin analogues, pegvisomant or a combination), or combined surgical and medical therapies. In a multivariable model, we assessed the prognostic impact of radiotherapy. We combined acute events (AMI, VTE and stroke) and chronic conditions (sleep apnoea, HF, arthropathy and DM) to gain precision for this specific analysis.

Table 1 Baseline characteristics at time of diagnosis of patients with acromegaly and the population comparison cohort.

\begin{tabular}{|c|c|c|c|c|}
\hline & \multicolumn{2}{|c|}{ Acromegaly cohort } & \multicolumn{2}{|c|}{ Comparison cohort } \\
\hline & $n$ & Percent (\%) & $n$ & Percent (\%) \\
\hline All & 405 & 100 & 4050 & 100 \\
\hline \multicolumn{5}{|l|}{ Sex } \\
\hline Male & 214 & 53 & 2140 & 53 \\
\hline Female & 191 & 47 & 1910 & 47 \\
\hline \multicolumn{5}{|c|}{ Age distribution } \\
\hline$<35$ years & 77 & 19 & 782 & 19 \\
\hline $35-45$ & 98 & 24 & 970 & 24 \\
\hline $45-55$ & 97 & 24 & 976 & 24 \\
\hline $55-65$ & 70 & 17 & 688 & 17 \\
\hline$\geq 65$ & 63 & 16 & 634 & 16 \\
\hline \multicolumn{5}{|l|}{ Diabetes } \\
\hline No & 357 & 88 & 3959 & 98 \\
\hline Yes & 48 & 12 & 91 & 2 \\
\hline \multicolumn{5}{|c|}{ Hypertension } \\
\hline No & 361 & 89 & 3903 & 96 \\
\hline Yes & 44 & 11 & 147 & 4 \\
\hline \multicolumn{5}{|c|}{ Chronic obstructive pulmonary disease } \\
\hline No & 392 & 97 & 3927 & 97 \\
\hline Yes & 13 & 3 & 123 & 3 \\
\hline \multicolumn{5}{|c|}{ Liver disease or chronic pancreatitis } \\
\hline No & 401 & 99 & 3922 & 97 \\
\hline Yes & 4 & 1 & 128 & 3 \\
\hline
\end{tabular}

The proportional-hazards assumption was assessed graphically for all outcome variables and found valid. Analyses were performed using STATA version 13.1 and SAS version 9.3.

\section{Results}

\section{Patient characteristics}

The study included 405 acromegaly patients and 4050 ageand gender-matched general population cohort members, of whom $47 \%$ were women. Mean age at diagnosis was 48.7 years (95\% CI: 47.2-50.1), which was unchanged over time (Fig. 1A). Mean diagnostic $\mathrm{GH}_{\text {nadir }}$ and IGF-ISDS results were $10.3 \mu \mathrm{g} / \mathrm{L}$ (95\% CI: 8.8-12.1) and +5.2 SDS (95\% CI: 4.9-5.4) respectively. Among acromegaly patients for whom details of the radiological assessment were available $(n=285), 197(69 \%)$ had a pituitary macroadenoma ( $\geq 10 \mathrm{~mm})$ and $88(31 \%)$ a microadenoma $(<10 \mathrm{~mm})$ (Table 1$)$.

A weak inverse correlation was found between age at diagnosis and adenoma diameter $\left(R^{2}=0.09, P<0.01\right)$. We recorded positive correlations between adenoma size and $\mathrm{GH}_{\text {nadir }}$ level $\left(R^{2}=0.11, P<0.01\right)$ and between adenoma size and IGF-I-SDS level $\left(R^{2}=0.08, P<0.01\right)$ respectively. Correspondingly, we observed that younger patients ( $<50$ th percentile) compared with older patients had larger adenomas (19.5 vs $10.0 \mathrm{~mm}, P<0.01)$, higher

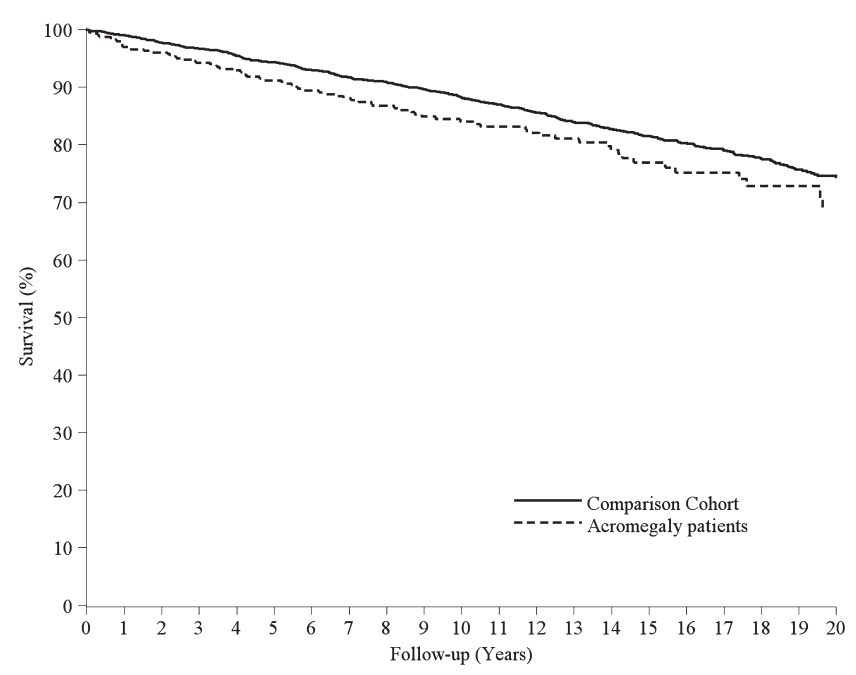

\section{Figure 2}

Kaplan-Meier analysis of observed mortality rates among patients with acromegaly (dotted line) and for a matched comparison cohort (solid line). 
IGF-I-SDS levels (5.7 vs 5.0 SDS, $P<0.00$ ), and higher $\mathrm{GH}_{\text {nadir }}$ levels $(14.0$ vs $7.2 \mu \mathrm{g} / \mathrm{L}, P<0.01)$ at time of diagnosis. There was a similar sex distribution in the younger and older groups (data not shown). Male patients had higher $\mathrm{GH}_{\text {nadir }}$ levels (10.1 vs $7.9 \mu \mathrm{g} / \mathrm{L}$, $P=0.09$ ) and higher IGF-I-SDS levels (5.5 vs $4.9, P<0.01$ ) at diagnosis, although adenoma size $(15.8$ vs $15.0 \mathrm{~mm}$, $P=0.51$ ) and age at diagnosis (48.6 vs 48.0 years, $P=0.62$ ) were comparable for males and females. Eighty percent were surgically treated, $56 \%$ of whom received additional medical treatment for acromegaly. The remaining $20 \%$ of the patient cohort received primary medical therapy. In the total cohort, $17 \%$ received radiation therapy.

\section{Incidence and prevalence}

The mean annual incidence rate of acromegaly was 3.8 (95\% CI 3.7-4.0) cases $/ 10^{6}$ persons, remaining stable over calendar time. The point prevalence in 2010 was 85 cases $/ 10^{6}$ persons based on 469 acromegaly patients and a general population of 5534738 persons (Fig. 1B).

\section{Mortality}

During the follow-up period (mean follow-time 10.6years), 73 patients with acromegaly died (18\%). The mortality rate was higher in acromegaly patients (17.5/1000 personyears, 95\% CI: 13.9-22.0) compared with the general

Table 2 Rates and hazard ratios with $95 \%$ confidence intervals ( $95 \% \mathrm{Cls})$ for the risk of selected comorbidity in patients with acromegaly, stratified by follow-up time.

\begin{tabular}{|c|c|c|c|c|c|}
\hline \multirow[b]{2}{*}{ Outcome } & \multirow{2}{*}{$\begin{array}{l}\text { Period } \\
\text { (years before/after diagnosis) }\end{array}$} & \multicolumn{2}{|c|}{$\begin{array}{c}\text { Rate } \\
(95 \% \mathrm{Cl}) \text { per } 1000 \text { person-years }\end{array}$} & \multicolumn{2}{|c|}{ Hazard ratio $(95 \% \mathrm{Cl})$} \\
\hline & & Acromegaly cohort & Control cohort & Age- and sex-adjusted model & Fully adjusted model ${ }^{2}$ \\
\hline \multirow[t]{4}{*}{ Heart failure } & $0-3$ years before & $8.3(4.5-15.5)$ & $0.8(0.4-1.5)$ & $9.8(4.1-23.7)$ & $8.5(2.8-25.7)$ \\
\hline & At diagnosis & $4.7(3.0-7.4)$ & $2.0(1.6-2.5)$ & $2.7(1.6-4.5)$ & $2.5(1.4-4.5)$ \\
\hline & 0-1 year after & $10.4(3.9-27.7)$ & $1.5(0.7-3.3)$ & $7.5(2.0-28.1)$ & $6.9(1.6-28.5)$ \\
\hline & $1-30$ years after & $4.1(2.5-6.9)$ & $2.0(1.6-2.5)$ & $2.2(1.3-4.0)$ & $2.1(1.1-3.9)$ \\
\hline \multirow[t]{4}{*}{ AMI } & $0-3$ years before & $5.0(2.3-11.2)$ & $1.2(0.7-2.0)$ & $4.4(1.7-11.5)$ & $5.5(1.8-16.7)$ \\
\hline & At diagnosis & $3.2(1.9-5.6)$ & $2.9(2.4-3.5)$ & $1.2(0.7-2.2)$ & $1.0(0.5-1.9)$ \\
\hline & $0-1$ year after & $2.6(0.4-18.4)$ & $3.3(1.9-5.7)$ & $1.0(0.1-7.5)$ & $1.2(0.1-10.0)$ \\
\hline & $1-30$ years after & $3.3(1.9-5.8)$ & $2.9(2.4-3.5)$ & $1.3(0.7-2.3)$ & $1.0(0.5-2.0)$ \\
\hline \multirow[t]{4}{*}{ Diabetes mellitus } & $0-3$ years before & $30.3(21.8-42.2)$ & $1.9(1.3-2.9)$ & $17.8(10.2-31.0)$ & $23.2(12.0-44.9)$ \\
\hline & At diagnosis & $12.1(9.0-16.4)$ & $3.4(2.9-4.1)$ & $4.1(2.8-5.8)$ & $4.0(2.7-5.8)$ \\
\hline & 0-1 year after & $37.7(21.9-65.0)$ & $2.6(1.4-4.7)$ & $14.0(6.0-32.7)$ & $21.8(7.5-63.2)$ \\
\hline & $1-30$ years after & $9.3(6.5-13.4)$ & $3.5(3.0-4.2)$ & $3.0(2.0-4.7)$ & $2.9(1.9-4.5)$ \\
\hline \multirow[t]{4}{*}{ Stroke } & $0-3$ years before & $5.0(2.2-11.0)$ & $1.9(1.3-2.9)$ & $2.6(1.1-6.4)$ & $2.1(0.7-5.8)$ \\
\hline & At diagnosis & $4.0(2.4-6.5)$ & $3.2(2.7-3.8)$ & $1.3(0.8-2.2)$ & $1.1(0.6-2.0)$ \\
\hline & 0-1 year after & NE & $2.5(1.4-4.7)$ & NE & NE \\
\hline & 1-30years after & $4.4(2.7-7.2)$ & $3.3(2.8-3.9)$ & $1.4(0.8-2.4)$ & $1.3(0.7-2.3)$ \\
\hline \multirow[t]{4}{*}{ Arthropathy } & $0-3$ years before & $16.5(10.4-26.1)$ & $8.2(6.7-10.1)$ & $2.0(1.2-3.3)$ & $1.9(1.1-3.2)$ \\
\hline & At diagnosis & $27.6(22.5-34.0)$ & 13.3 (12.2-14.5) & $2.2(1.7-2.8)$ & $2.1(1.6-2.6)$ \\
\hline & 0-1 year after & 11.5 (4.3-30.7) & 13.5 (10.2-17.9) & $0.9(0.3-2.5)$ & $0.8(0.3-2.2)$ \\
\hline & 1-30years after & $29.6(23.9-36.6)$ & 13.3 (12.1-14.6) & $2.3(1.8-3.0)$ & $2.2(1.7-2.9)$ \\
\hline \multirow[t]{4}{*}{ Sleep apnoea } & $0-3$ years before & $11.0(6.4-19.0)$ & $0.4(0.2-1.0)$ & $25.9(9.2-72.5)$ & 47.6 (11.8-191.9) \\
\hline & At diagnosis & $9.8(7.1-13.5)$ & $0.9(0.7-1.2)$ & $11.6(7.1-18.7)$ & 11.7 (7.0-19.4) \\
\hline & 0-1 year after & $21.4(10.7-42.7)$ & $0.2(0.0-1.8)$ & $80.0(10.0-639.6)$ & NE \\
\hline & $1-30$ years after & $8.5(5.9-12.3)$ & $1.0(0.7-1.3)$ & $9.3(5.5-15.5)$ & $9.3(5.4-16.0)$ \\
\hline \multirow[t]{4}{*}{ VTE } & $0-3$ years before & $1.7(0.4-6.6)$ & $1.0(0.6-1.8)$ & $1.7(0.4-7.4)$ & $1.5(0.3-7.6)$ \\
\hline & At diagnosis & $2.4(1.3-4.5)$ & $1.1(0.8-1.4)$ & $2.2(1.1-4.4)$ & $2.3(1.1-5.0)$ \\
\hline & 0-1 year after & NE & $1.3(0.5-3.0)$ & NE & NE \\
\hline & $1-30$ years after & $2.7(1.4-5.0)$ & $1.1(0.8-1.4)$ & $2.5(1.2-5.1)$ & $2.5(1.1-5.5)$ \\
\hline \multirow[t]{4}{*}{ Fracture } & $0-3$ years before & $7.8(4.1-15.1)$ & $6.4(5.1-8.0)$ & $1.2(0.6-2.3)$ & $1.3(0.7-2.7)$ \\
\hline & At diagnosis & $7.0(4.8-10.2)$ & $8.4(7.5-9.3)$ & $0.9(0.6-1.3)$ & $0.8(0.5-1.2)$ \\
\hline & 0-1 year after & $10.8(4.0-28.7)$ & $5.9(3.9-9.0)$ & $1.8(0.6-5.2)$ & $1.3(0.4-4.3)$ \\
\hline & 1-30years after & 6.6 (4.4-9.9) & $8.6(7.7-9.7)$ & $0.8(0.5-1.2)$ & $0.7(0.5-1.1)$ \\
\hline
\end{tabular}

$\mathrm{NE}$, not estimated.

aModel adjusted for age, sex, calendar time and baseline imbalances including hypertension, diabetes mellitus, cancer, smoke and alcoholism-related diseases. 
population cohort (13.5/1000 person-years, 95\% CI: 12.4-14.6), with an adjusted HR of 1.3 (95\% CI: 1.0-1.7) (Fig. 2). The HR for mortality was higher in the first year after diagnosis (HR: 2.6 (95\% CI: 1.2-5.6)) compared with subsequent years (HR: 1.2 (95\% CI: 0.9-1.6)). Cancerspecific mortality was not clearly increased in acromegaly (HR: 1.1 (95\% CI: 0.7-1.9)), whereas cardiovascular mortality was increased (HR: 1.6 (95\% CI: 1.0-2.5)). The HR for any other causes was 1.4 (95\% CI: 0.9-2.1).

When stratified by age, the HR was higher in the younger group (HR: 2.2 (95\% CI: 1.1-4.3)) than in the older group (HR: 1.2 (95\% CI: 0.9-1.6)), but similar in males and females. Mortality risk was not related to baseline IGF-I $(P=0.93)$ or GH-nadir $(P=0.61)$ at baseline (Appendix 2).

\section{Cardiometabolic complications}

Acromegaly patients were at increased risk of diabetes mellitus (HR: 4.0 (95\% CI: 2.7-5.8)), heart failure (HR: 2.5 (95\% CI: 1.4-4.5)) and VTE (HR: 2.3 (95\% CI: 1.1-5.0)), while risk of stroke (HR: 1.1 (95\% CI: 0.6-2.0)) and AMI (1.0 (95\% CI: 0.5-1.9)) was unaffected. For heart failure and diabetes mellitus, the risks were most pronounced in the 3-year period before diagnosis. There was a subsequent decrease starting in the first year after diagnosis (Table 2). In addition, AMI risk was increased in the prediagnostic period (HR: 5.5 (95\% CI: 1.8-16.7)). In the younger group, the risk of diabetes mellitus (HR: 4.8 (95\% CI: 2.5-9.2)), heart failure (HR: 8.2 (95\% CI: 2.8-24.5)) and VTE (HR: 4.4 (95\% CI: 1.512.9)) remained increased, while in the older group, mainly the risk of diabetes mellitus was increased (HR: 3.2 (95\% CI: 2.0-5.3; Table 3)). Of note, absolute risks for all events were higher in the older group. None of the VTE events occurred within 3 months after surgery. The overall risk for hypertension was increased, which largely was recorded in the first year after the diagnosis; however, the risk remained increased when excluding the first year after the diagnosis (HR: 8.8 (95\% CI: 6.3-12.2)). The risk of hypertension also prevailed in the 3-year period before diagnosis (HR: 9.5 (C95\% CI: 5.9-15.2)) (Fig. 3, Tables 2 and 3).

\section{Sleep apnoea, arthropathy and fracture risk}

For acromegaly patients, the overall risks of sleep apnoea (HR: 11.7 (95\% CI: 7.0-19.4)) and arthropathy (HR: 2.1 (95\% CI: 1.6-2.6)) were increased, but not the overall risk of fractures (HR: 0.5 (95\% CI: 0.5-1.2)). When the analysis was stratified by age at diagnosis, the older group had a higher risk of sleep apnoea (HR: 13.3 (95\% CI: 5.9-30.0)) and arthropathy (HR: 2.5 (95\% CI: 1.8-3.4)). However, these risks were also increased in the younger group. The risk of fractures was not elevated in either group. Higher levels of IGF_I (HR: 1.38 (95\% CI: 0.67-2.82)) and GH ((HR: 1.29 (95\% CI: 1.06-1.56)) at baseline seemed associated with increased arthropathy risk (Appendix 2) (Fig. 3, Tables 2 and 3).

\section{Cancer}

In the acromegaly cohort, overall cancer risk tended to be increased (HR: 1.4 (95\% CI: 0.9-2.2)); no increased risk for colorectal cancer (HR: 1.1 (95\% CI: 0.4-2.9)), breast cancer (HR: 1.0 (95\% CI: 0.4-2.8)) or lung cancer (HR: 0.9 (95\% CI: 0.3-3.0)) was evident.

\section{Mortality and morbidity outcome according to therapy}

For the analyses based on treatment, we defined treatment (strategies) 2 years after initial diagnosis. Of all patients still in follow-up after 2 years $(n=387)$, 171 patients were treated by surgery only, 102 by a combination of surgery and medication, and 62 by medication only. Long-term mortality risks were similar in the three groups, and no significant differences were found when comparing the three groups for acute cardiovascular events (AMI, VTE and stroke) or chronic conditions. In a multivariable model, radiotherapy

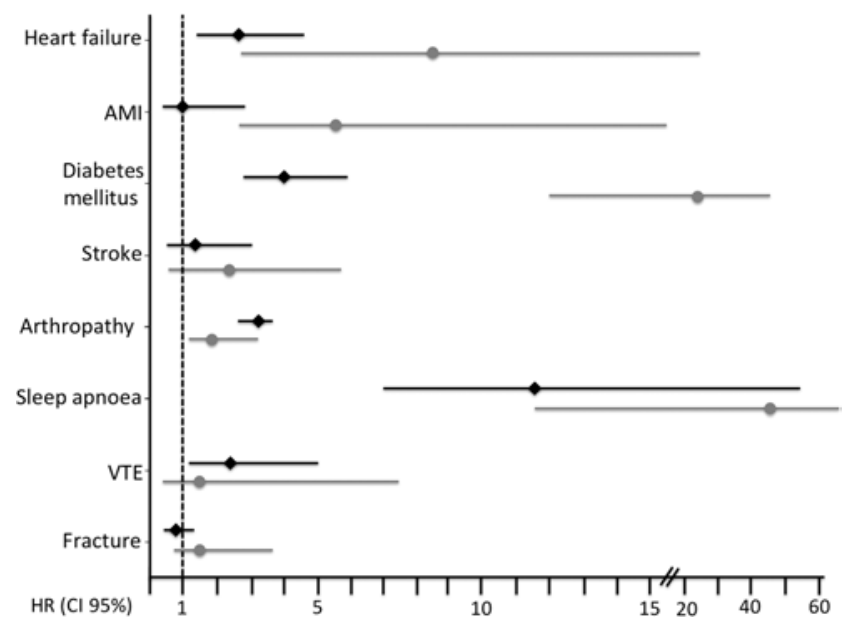

Figure 3

Hazard ratio for development of complications in acromegaly compared with a matched comparison cohort. Overall risk (black) and the 3-year prediagnostic risk (grey) with 95\% confidence intervals. 
was not clearly associated with mortality $(P=0.6)$ or cardiovascular disease (0.2) (Appendix 3).

\section{Discussion}

This population-based cohort study was conducted to provide updated, accurate estimates regarding the epidemiology of acromegaly, including age at diagnosis, incidence and prevalence rates, and rates of complications and mortality. The strengths of our study include its population-based design with a general population comparison cohort and linkage among multiple healthrelated registries using a unique identifier.

We found an average annual incidence rate of acromegaly of approximately 4 cases $/ 10^{6}$, which was constant over calendar time. This estimate lies within the range previously reported, albeit in the upper part of the range $(13,14,15,16,17,18,19,20,21,22,23$, $24,25)$. We estimated the point prevalence as 85 cases of acromegaly $/ 10^{6}$ persons in 2010, which is higher than most previous reports $(19,20,21,22,23,24,25)$. There is a theoretical basis for a true prevalence as high as 120 cases $/ 10^{6}$ persons, based on the estimated annual incidence rate of 3.8 cases $/ 10^{6}$, an average age at diagnosis of 48.3 years, and a life expectancy slightly below that of the general population (78 years). This theoretical prevalence is in line with two recent publications based on small cohorts (7-9 cases) $(15,18)$.

Interestingly, the age at diagnosis did not decline during the 20-year calendar period of our study. This, together with the constant incidence rate, seems to suggest that diagnostic awareness is not increasing and that there has been no major effect of novel and more sensitive diagnostic work-up on acromegaly detection.

Although neither adenoma size nor age at diagnosis differed by gender, diagnostic GH and IGF-I levels were higher among males. In accordance with this finding, data from Finland showed slightly higher basal GH levels in male patients (26), and a German study reported a higher random GH level in male patients, who were also younger at diagnosis (27). However, another study reported that for a given GH level, female patients with active acromegaly had lower serum IGF-I levels compared with males. This was partly attributed to the suppressive effect of oestrogen on hepatic IGF-I production (28), but this study mainly included patients with residual disease activity after surgery and radiation therapy (28). Collectively, the data suggest that biochemical disease activity at diagnosis is greater in male compared with female patients. This was not explained by age or adenoma size at time of diagnosis. 
We showed increased complications in acromegaly patients, supporting previously published data $(19,29)$. Because this risk was most pronounced during the first year after diagnosis, it is possible that detection bias (detecting diseases due to the fact that patients come to medical attention) may have contributed to this finding. In particular, we believe that hypertension is subject to detection bias. It should also be noted that a constellation of symptoms may lead to a diagnosis of acromegaly, and the other way around, in patients with acromegaly, clinicians will search for acromegaly-related complications.

Importantly, however, increased morbidity was also evident in the 3-year prediagnostic period, adding new support to observations that the prediagnostic phase of acromegaly is sizeable and contributes to morbidity (27, 30, 31, 32, 33). This phenomenon, and also the highest mortality risk in the first year after diagnosis, might point towards reduction in morbidity and mortality due to effective treatment.

Risk of arthropathy was highest during long-term follow-up, which may reflect the slow and progressive effects of GH and IGF-I on this condition (34). GH excess also has been linked to the development of hypercoagulation and venous thrombosis (35). In accordance with this, we recorded a slightly increased risk of VTE in our study. In contrast to previous studies (36), we did not observe an increased risk of stroke. One potential explanation could be the limited use of pituitary irradiation in Denmark (only $17 \%$ in this cohort), as this treatment has been linked to late onset cerebrovascular damage and hence increased risk of stroke (36).

Vertebral fractures have been reported to be common among patients with acromegaly (37), and the risk of osteoporotic fractures has been linked to hypogonadism (38). However, we found no increase in the risk of fractures among our patients. This lacking association could reflect that vertebral fracture are largely asymptomatic and under-diagnosed (37).

Whether acromegaly is associated with an increased risk of cancer remains controversial (39), but most epidemiological studies have reported an increased risk of colorectal cancer $(5,40)$. While we observed only an increased overall cancer risk (HR: 1.4), the confidence intervals preclude a definitive resolution of this dispute. To gain statistical power, it would be of great relevance to perform a study focussing on cancer risk with prolonged follow-up in combination with a meta-analysis of published data.
We observed an inverse association between age at diagnosis and adenoma size, as well as biochemical disease activity, which is in accordance with other studies $(41,42,43)$. It has been suggested that the aetiology and pathogenesis of acromegaly may differ according to age at diagnosis, with more aggressive disease in young patients (44). To explore this, we stratified the cohort according to age at diagnosis and compared the risk of selected complications. In general, we found a higher relative risk in the younger group, especially as regards heart failure, diabetes mellitus and VTE. However, absolute risks remained highest in the older group. In contrast, the relative risks of arthropathy and sleep apnoea were highest in the older group, suggesting that these complications develop slowly. Although males were exposed to higher prediagnostic hormone levels, this did not translate into an increased risk of complications. In fact, risks of heart failure and diabetes mellitus were higher in females.

Mortality in patients with acromegaly has been examined in several studies and meta-analyses. The data suggest that the increased mortality risk has declined in recent years, attributed to improved treatment $(2,3)$. In our cohort, the overall mortality risk was only slightly elevated and in agreement with the literature $(2,3)$. We recorded an increased mortality from cardiovascular disease but not from cancer, which agrees with a metaanalysis from 2008 (2), although recent surveys from single centres report increased cancer mortality (45) and low prevalence of cardiac disease (46) respectively. Moreover, in a subanalysis, we did not record a significant impact of a given treatment strategy on mortality risk, acute cardiovascular event or chronic complications. To minimize the risk of immortal time bias, we categorized treatment after 2 years of initial diagnosis, and we excluded the small number of patients receiving irradiation. These data should be interpreted with caution and do not allow conclusion regarding the optimal treatment. For instance, it is likely that patients receiving a combination of treatments represent therapeutic challenges as compared with patients receiving surgery alone, and it is also likely that patients only receiving medical treatment differ from surgery-alone patients as regards operability. Nevertheless, we consider it reassuring that the prognosis after medical treatment alone or in combination with surgery is comparable to surgery alone.

In conclusion, this population-based cohort study provided novel and robust estimates of the incidence rate and prevalence of acromegaly. The observation that both the incidence rate and the age at diagnosis remained stable during the follow-up period, despite improvements in 
diagnostic tools, merits consideration. Our design allowed a thorough investigation of disease-related complications, which was prevalent before diagnosis and remained elevated throughout the follow-up period. We believe that our data have implications for proper allocation of health care resources and individual management of patients with acromegaly.

Appendix

This is linked to the online version of the paper at http://dx.doi.org/10.1530/ EJE-16-0117.

\section{Declaration of interest}

J D has received lecture fees from IPSEN, Novartis and Pfizer. U F R has received unrestricted grants from Pfizer and lecture fees from IPSEN, Novartis and Pfizer. $\mathrm{L} \varnothing \mathrm{K}$ is a member of an advisory board for Novartis. $P L$ is on the advisory board, is a clinical investigator and is a teacher for Novartis. J O L J has received unrestricted grants and lecture fees from IPSEN, Novartis and Pfizer and served on advisory boards for Novartis and Pfizer. M A, L P, O M D and H T S have nothing to declare.

\section{Funding}

This study was supported by grants from Pfizer and IPSEN.

\section{References}

1 Ben-Shlomo A \& Melmed S. Acromegaly. Endocrinology and Metabolism Clinics of North America 200837 101-122. (doi:10.1016/ j.ecl.2007.10.002)

2 Dekkers OM, Biermasz NR, Pereira AM, Romijn JA \& Vandenbroucke JP. Mortality in acromegaly: a metaanalysis. Journal of Clinical Endocrinology and Metabolism 200893 61-67. (doi:10.1210/jc.2007-1191)

3 Holdaway IM. Excess mortality in acromegaly. Hormone Research 200768 (Supplement 5) 166-172. (doi:10.1159/000110617)

4 Holdaway IM. Factors influencing mortality in acromegaly. Journal of Clinical Endocrinology and Metabolism 200489 667-674. (doi:10.1210/ jc.2003-031199)

5 Ayuk J \& Sheppard MC. Does acromegaly enhance mortality? Reviews in Endocrine and Metabolic Disorders 20089 33-39. (doi:10.1007/s11154-007-9067-8)

6 Giustina A, Chanson P, Bronstein MD, Klibanski A, Lamberts S, Casanueva FF, Trainer P, Ghigo E, Ho K \& Melmed S. A consensus on criteria for cure of acromegaly. Journal of Clinical Endocrinology and Metabolism 201095 3141-3148. (doi:10.1210/jc.2009-2670)

7 Giustina A, Chanson P, Kleinberg D, Bronstein MD, Clemmons DR, Klibanski A, van der Lely AJ, Strasburger CJ, Lamberts SW, Ho KKY et al. Expert consensus document: a consensus on the medical treatment of acromegaly. Nature Reviews Endocrinology 201410 243-248. (doi:10.1038/nrendo.2014.21)

8 Lynge E, Sandegaard JL \& Rebolj M. The Danish National Patient Register. Scandinavian Journal of Public Health 201139 (Supplement 7) 30-33. (doi:10.1177/1403494811401482)

9 Helweg-Larsen K. The Danish register of causes of death. Scandinavian Journal of Public Health 201139 (Supplement 7) 26-29. (doi:10.1177/1403494811399958)

10 Frank L. Epidemiology When an entire country is a cohort. Science 2000287 2398-2399. (doi:10.1126/science.287.5462.2398)
11 Dal J, Skou N, Nielsen EH, Jørgensen JOL \& Pedersen L. Acromegaly according to the Danish National Registry of Patients: how valid are ICD diagnoses and how do patterns of registration affect the accuracy of registry data? Clinical Epidemiology 20146 295-299. (doi:10.2147/ CLEP.S63758)

12 Suissa S. Immortal time bias in pharmaco-epidemiology. American Journal of Epidemiology 2008167 492-499. (doi:10.1093/aje/kwm324)

13 Tjörnstrand A, Gunnarsson K, Evert M, Holmberg E, Ragnarsson O, Rosén T \& Filipsson Nyström H. The incidence rate of pituitary adenomas in western Sweden for the period 2001-2011. European Journal of Endocrinology 2014171 519-526. (doi:10.1530/EJE-14-0144)

14 Kwon O, Song YD, Kim SY \& Lee EJ. Nationwide survey of acromegaly in South Korea. Clinical Endocrinology 201378 577-585. (doi:10.1111/cen.2013.78.issue-4)

15 Fernandez A, Karavitaki N \& Wass JAH. Prevalence of pituitary adenomas: a community-based, cross-sectional study in Banbury (Oxfordshire, UK). Clinical Endocrinology 201072 377-382. (doi:10.1111/cen.2010.72.issue-3)

16 Raappana A, Koivukangas J, Ebeling T \& Pirilä T. Incidence of pituitary adenomas in Northern Finland in 1992-2007. Journal of Clinical Endocrinology and Metabolism 201095 4268-4275. (doi:10.1210/jc.2010-0537)

17 Carlsen SM, Lund-Johansen M, Schreiner T, Aanderud S, Johannesen O, Svartberg J, Cooper JG, Hald JK, Fougner SL \& Bollerslev J. Preoperative octreotide treatment in newly diagnosed acromegalic patients with macroadenomas increases cure short-term postoperative rates: a prospective, randomized trial. Journal of Clinical Endocrinology and Metabolism 200893 2984-2990. (doi:10.1210/jc.2008-0315)

18 Daly AF, Rixhon M, Adam C, Dempegioti A, Tichomirowa MA $\&$ Beckers A. High prevalence of pituitary adenomas: a crosssectional study in the province of Liege, Belgium. Journal of Clinical Endocrinology and Metabolism 200691 4769-4775. (doi:10.1210/ jc.2006-1668)

19 Bex M, Abs R, T’Sjoen G, Mockel J, Velkeniers B, Muermans K \& Maiter D. AcroBel - the Belgian registry on acromegaly: a survey of the "real-life" outcome in 418 acromegalic subjects. European Journal of Endocrinology 2007157 399-409. (doi:10.1530/EJE-07-0358)

20 Mestrón A, Webb SM, Astorga R, Benito P, Catalá M, Gaztambide S, Gómez JM, Halperín I, Lucas-Morante T, Moreno B et al. Epidemiology, clinical characteristics, outcome, morbidity and mortality in acromegaly based on the Spanish Acromegaly Registry (Registro Español de Acromegalia, REA). European Journal of Endocrinology 2004151 439-446. (doi:10.1530/eje.0.1510439)

21 Holdaway IM \& Rajasoorya C. Epidemiology of acromegaly. Pituitary 19992 29-41. (doi:10.1023/A:1009965803750)

22 Etxabe J, Gaztambide S, Latorre P \& Vazquez JA. Acromegaly: an epidemiological study. Journal of Endocrinological Investigation 1993 16 181-187. (doi:10.1007/BF03344942)

23 Ritchie CM, Atkinson AB, Kennedy AL, Lyons AR, Gordon DS, Fannin T \& Hadden DR. Ascertainment and natural history of treated acromegaly in Northern Ireland. Ulster Medical Journal 199059 55-62.

24 Bengtsson BA, Edén S, Ernest I \& Odén A, Sjögren B. Epidemiology and long-term survival in acromegaly. A study of 166 cases diagnosed between 1955 and 1984. Acta Medica Scandinavica 1988223 327-335. (doi:10.1111/j.0954-6820.1988.tb15881.x)

25 Alexander L, Appleton D, Hall R, Ross WM \& Wilkinson R. Epidemiology of acromegaly in the Newcastle region. Clinical Endocrinology 198012 71-79. (doi:10.1111/j.1365-2265.1980. tb03135.x)

26 Kauppinen-Mäkelin R, Sane T, Reunanen A, Välimäki MJ, Niskanen L, Markkanen H, Löyttyniemi E, Ebeling T, Jaatinen P, Laine H et al. A nationwide survey of mortality in acromegaly. Journal of Clinical Endocrinology and Metabolism 200590 4081-4086. (doi:10.1210/ jc.2004-1381)

27 Petersenn S, Buchfelder M, Gerbert B, Franz H, Quabbe HJ, Schulte HM, Grussendorf M \& Reincke M. Age and sex as predictors 
of biochemical activity in acromegaly: analysis of 1485 patients from the German Acromegaly Register. Clinical Endocrinology 200971 400-405. (doi:10.1111/cen.2009.71.issue-3)

28 Parkinson C, Ryder WD \& Trainer PJ. The relationship between serum GH and serum IGF-I in acromegaly is gender-specific. Journal of Clinical Endocrinology and Metabolism 200186 5240-5244.

29 Colao A. Systemic complications of acromegaly: epidemiology, pathogenesis, and management. Endocrine Reviews 200425 102-152. (doi:10.1210/er.2002-0022)

30 Holdaway IM. Factors influencing mortality in acromegaly. Journal of Clinical Endocrinology and Metabolism 200489 667-674. (doi:10.1210/ jc.2003-031199)

31 Arosio M, Reimondo G, Malchiodi E, Berchialla P, Borraccino A, De Marinis L, Pivonello R, Grottoli S, Losa M, Cannavò S et al. Predictors of morbidity and mortality in acromegaly: an Italian survey. European Journal of Endocrinology 2012167 189-198. (doi:10.1530/EJE-12-0084)

32 Fieffe S, Morange I, Petrossians P, Chanson P, Rohmer V, Cortet C, Borson-Chazot F, Brue T \& Delemer B. Diabetes in acromegaly, prevalence, risk factors, and evolution: data from the French Acromegaly Registry. European Journal of Endocrinology 2011164 877-884. (doi:10.1530/EJE-10-1050)

33 Reid TJ, Post KD, Bruce JN, Nabi Kanibir M, Reyes-Vidal CM \& Freda PU. Features at diagnosis of 324 patients with acromegaly did not change from 1981 to 2006: acromegaly remains under-recognized and under-diagnosed. Clinical Endocrinology 201072 203-208. (doi:10.1111/cen.2010.72.issue-2)

34 Romijn JA. Acromegalic arthropathy: current perspectives. Endocrine 201343 245-246. (doi:10.1007/s12020-012-9781-1)

35 Erem C, Nuhoglu I, Kocak M, Yilmaz M, Sipahi ST, Ucuncu O \& Ersoz HO. Blood coagulation and fibrinolysis in patients with acromegaly: increased plasminogen activator inhibitor-1 (PAI-1), decreased tissue factor pathway inhibitor (TFPI), and an inverse correlation between growth hormone and TFPI. Endocrine 200833 270-276. (doi:10.1007/s12020-008-9088-4)

36 Ayuk J. Growth hormone and pituitary radiotherapy, but not serum insulin-like growth factor-I concentrations, predict excess mortality in patients with acromegaly. Journal of Clinical Endocrinology and Metabolism 200489 1613-1617. (doi:10.1210/jc.2003-031584)

37 Mazziotti G, Bianchi A, Bonadonna S, Cimino V, Patelli I, Fusco A, Pontecorvi A, De Marinis L \& Giustina A. Prevalence of vertebral fractures in men with acromegaly. Journal of Clinical Endocrinology and Metabolism 200893 4649-4655. (doi:10.1210/jc.2008-0791)

38 Zgliczynski W, Kochman M, Misiorowski W \& Zdunowski P. In acromegaly, increased bone mineral density (BMD) is determined by GH-excess, gonadal function and gender. Neuro Endocrinology Letters 200728 621-628.

39 Loeper S \& Ezzat S. Acromegaly: re-thinking the cancer risk. Reviews in Endocrine and Metabolic Disorders 20089 41-58. (doi:10.1007/ s11154-007-9063-z)

40 Yamamoto M, Fukuoka H, Iguchi G, Matsumoto R, Takahashi M, Nishizawa H, Suda K, Bando H \& Takahashi Y. The prevalence and associated factors of colorectal neoplasms in acromegaly: a single center based study. Pituitary 201518 343-351. (doi:10.1007/ s11102-014-0580-y)

41 Van der Lely AJ, Harris AG \& Lamberts SW. The sensitivity of growth hormone secretion to medical treatment in acromegalic patients: influence of age and sex. Clinical Endocrinology 199237 181-185. (doi:10.1111/j.1365-2265.1992.tb02304.x)

42 Doyle FH, Fraser TR \& Joplin GF. The acromegaly syndrome. Quarterly Journal of Medicine $1982 \mathbf{5 1}$ 189-204.

43 Anagnostis P, Efstathiadou ZA, Polyzos SA, Adamidou F, Slavakis A, Sapranidis M, Litsas ID, Katergari S, Selalmatzidou D \& Kita M. Acromegaly: presentation, morbidity and treatment outcomes at a single centre. International Journal of Clinical Practice 201165 896-902. (doi:10.1111/j.1742-1241.2011.02682.x)

44 Cuevas-Ramos D, Carmichael JD, Cooper O, Bonert VS, Gertych A, Mamelak AN \& Melmed S. A structural and functional acromegaly classification. Journal of Clinical Endocrinology and Metabolism 2015 100 122-131. (doi:10.1210/jc.2014-2468)

45 Mercado M, Gonzalez B, Vargas G, Ramirez C, de los Monteros ALE, Sosa E, Jervis P, Roldan P, Mendoza V, López-Félix B et al. Successful mortality reduction and control of comorbidities in patients with acromegaly followed at a highly specialized multidisciplinary clinic. Journal of Clinical Endocrinology and Metabolism 201499 4438-4446. (doi:10.1210/jc.2014-2670)

46 Dos Santos Silva CM, Gottlieb I, Volschan I, Kasuki L, Warszawski L, Balarini Lima GA, Xavier SS, Pedrosa RC, Neto LV \& Gadelha MR. Low frequency of cardiomyopathy using cardiac magnetic resonance imaging in an acromegaly contemporary cohort. Journal of Clinical Endocrinology and Metabolism 2015100 4447-4455. (doi:10.1210/ jc.2015-2675)

Received 15 February 2016

Revised version received 25 April 2016

Accepted 26 May 2016 